\title{
Resolution of ST-Segment Depression in Reciprocal Leads as Predictor Mayor Adverse Cardiac Event for ST-Segment Elevation Myocardial Infarction with Fibrinolytic Therapy
}

\author{
Aldino Satria Adhitya, Harris Hasan, Andika Sitepu, Zulfikri Mukhtar
}

Departemen Kardiologi dan Kedokteran Vaskular, Fakultas Kedokteran Universitas Sumatera Utara, Rumah Sakit Umum Haji Adam Malik, Medan, Indonesia

\section{Correspondence:} dr. Aldino Satria Adhitya, Program Pendidikan Dokter Spesialis-I Departemen Kardiologi dan Kedokteran Vaskular,

Fakultas Kedokteran Universitas Sumatera Utara, Rumah Sakit Umum Haji Adam Malik, Medan, Indonesia.

E-mail: orlandosatria@gmail. com

\begin{abstract}
Background: ST Elevation Myocardial Infarction (STEMI) may cause Major Adverse Cardiovascular Event (MACE). Revascularization needs to be done in all STEMI patients to restore coronary blood flow, hence saving myocardial perfusion. ST Segment Depression (STSD) in reciprocal ECG lead is associated with poor prognosis in STEMI patients receiving fibrinolytic therapy. The main purpose of this study is to evaluate MACE in STEMI patients receiving fibrinolytic therapy using resolution in STSD.

Methods: This cohort prospective study with 60 subjects of STEMI patients which are evaluated for MACE (death, heart failure, and rehospitalization) within 30 days after myocardial infarction. Resolution in STSD is defined as resolution $\geq 50 \%$ STSD in reciprocal leads within 90 minutes after fibrinolytic therapy.

Results: Bivariate analysis showed that Ejection fraction (EF) $<40 \%$ with OR 8,32 (2,II-32,74), $\mathrm{p}=0,00 \mathrm{I}$; smoking with OR 4,I7 (I,05-16,57), $\mathrm{p}=0,034$; Anterior STEMI with OR 3,94 (I,II-I3,90), $\mathrm{p}=0,027$; Creatinine $>1,97 \mathrm{mg} / \mathrm{dl}$ with $O R$ $3,69(I, I 8-1 I, 55), p=0,022$; complete outpatient medication with OR 5,23 (I,6I$I 7,0 I), p=0,004$; fragmented QRS with OR 5,23 (I,6I-I 7,0I), $p=0,00 I$; resolution in STSD with OR 26,35 $(5,16-134,40), p=<0,001$; resolution in ST Segment Elevation with OR 10,5 (2,97-37,24), $\mathrm{p}=<0,00 \mathrm{I}$; are proven to be determining factor for MACE within 30 days. Multivariate analysis showed that among those determining factors for MACE, resolution in STSD on reciprocal leads is evidently the most dominant factor for predicting MACE within 30 days in STEMI patients receiving fibrinolytic therapy [OR II .47 (I.I4-I I 5. I0), p=0.038].

Conclusion: There is significant difference in MACE within 30 days after myocardial infarction (MI) between patients with and without resolution in STSD. The subjects without resolution in STSD showed higher MACE incidence. Resolution in STSD is evidently an independent predictor for MACE within 30 days after myocardial infarction in STEMI patients.
\end{abstract}

(Indonesian J Cardiol. 2018;39:68-78)

Keywords: Resolution in STSD, MACE, STEMI, Fibrinolytic 


\title{
Resolusi Depresi Segment ST Resiprokal sebagai Prediktor Kejadian Kardiovaskular Mayor pada Penderita Infark Miokard Akut Elevasi Segment ST yang Mendapatkan Terapi Fibrinolitik Alteplase
}

\author{
Aldino Satria Adhitya, Harris Hasan, Andika Sitepu, Zulfikri Mukhtar
}

\begin{abstract}
Abstrak
Latar Belakang: Infark Miokard Akut Elevasi Segment ST (IMAEST) dapat berakibat Kejadian Kardiovaskular Mayor (KKvM). Penderita IMAEST memerlukan tindakan revaskularisasi untuk mengembalikan aliran darah dan reperfusi miokard. Lebih banyak informasi bisa didapatkan dari EKG meliputi ukuran infark dan prognosis penderita IMAEST. Depresi Segment ST (DSST) di sadapan resiprokal pada EKG pasien IMAEST yang di terapi dengan fibrinolitik secara klinis dikaitkan dengan prognosis yang lebih buruk. Tujuan dari penelitian ini adalah untuk mencari perbandingan KKvM untuk subjek IMAEST yang mendapat terapi fibrinolitik dalam menilai prognosis yakni adanya resolusi DSST sesaat setelah fibrinolitik.

Metode: Penelitian ini merupakan studi kohort prospektif, dimana 60 orang subjek IMAEST, kemudian pasien diikuti kejadian KKVM (kematian, gagal jantung, rehospitalisasi) selama 30 hari paska IMAEST. Nilai Resolusi DSST resiprokal adalah penurunan $\geq 50 \%$ besaran DSST resiprokal pada pasien IMAEST 90 menit sejak awal dimulai terapi fibrinolitik.

Hasil: Analisis bivariat menunjukkan bahwa Fraksi Ejeksi < 40\% dengan OR 8,32 (2,11-32,74), p=0,001; Merokok dengan OR 4,17 (1,0516,57), p=0,034; Anterior IMAEST dengan OR 3,94 (1,11-13,90), p= 0,027; Kreatinin > 1,97 mg/dl dengan OR 3,69 (1,18-11,55), p= 0,22; Obat rawat jalan lengkap dengan OR 5,23 (1,61-17,01), p= 0,004; Fragmentasi QRS dengan OR 5,23 (1,61-17,01); Resolusi DSST dengan OR 26,35 (5,16-134, 40); resolusi STE dengan OR 10,5 (2,97-37,24); merupakan faktor-faktor yang bermakna terhadap KKvM dalam 30 hari. Pada analisis multivariat resolusi DSST resiprokal secara signifikan merupakan faktor yang dominan mempengaruhi KKvM dalam 30 hari setelah IMAEST yang mendapatkan terapi fibrinolitik alteplase [OR 11.47 (1.14-115.10), p=0.038].

Kesimpulan: Terdapat perbedaan KKvM 30 hari setelah IMAEST yang mendapatkan terapi fibrinolitik altepalse pada penderita IMAEST dengan dan tanpa resolusi DSST resiprokal, dimana angka KKvM yang lebih tinggi dijumpai pada penderita IMAEST tanpa resolusi DSST resiprokal. Resolusi DSST resiprokal pada IMAEST merupakan prediktor independen terhadap KKvM dalam 30 hari setelah IMAEST.
\end{abstract}

(Indonesian J Cardiol. 2018;39:68-78)

Kata kunci: Resolusi DSST resiprokal, KKvM, IMAEST, Fibrinolitik

Departemen Kardiologi dan Kedokteran Vaskular, Fakultas Kedokteran Universitas Sumatera Utara, Rumah Sakit Umum Haji Adam Malik, Medan, Indonesia

\section{Korespondensi:}

dr. Aldino Satria Adhitya

Program Pendidikan Dokter Spesialis-I Departemen Kardiologi dan Kedokteran Vaskular,

Fakultas Kedokteran Universitas Sumatera Utara,

Rumah Sakit Umum Haji Adam Malik, Medan, Indonesia.

E-mail: orlandosatria@gmail.com

\section{Pendahuluan}

厂 nfark Miokard Akut Elevasi Segmen ST (IMAEST) merupakan suatu bagian Sindroma Koroner Akut yang terjadi karena penyumbatan total arteri koroner oleh trombus yang terbentuk atau terlepas sebagai respon tubuh terhadap ruptur plak arteroskelosis, IMAEST dapat berakibat pada kematian mendadak bahkan sebelum sempat dibawa ke pelayanan kesehatan 
maupun Kejadian Kardiovaskular Mayor (KKvM) setelah dan selama perawatan. Bahkan sekarang ini angka KKvM pada populasi penderita IMAEST adalah berkisar 10,3\%, cukup besar untuk populasi penderita IMAEST yang telah menjalani tindakan reperfusi dini. ${ }^{1}$

Penderita IMAEST memerlukan tindakan revaskularisasi untuk mengembalikan aliran darah dan reperfusi miokard, yang dapat dilakukan dengan terapi fakmakologis (agen fibrinolitik) atau secara mekanis yaitu Intervensi Koroner Perkutan (IKP) primer. Terapi reperfusi IKP atau farmakologis, diindikasikan untuk semua pasien dengan onset gejala yang timbul dibawah 12 jam. 2,3 Di Rumah Sakit Haji Adam Malik Medan (RSHAM) tindakan reperfusi dini dilakukan 91\% dengan fibrinolitik4, namun angka keberhasilan serta follow up KKvM jangka panjang pasien pasca fibrinolitik belum pernah diteliti sebelumnya, pertama hal ini terkait dengan kriteria keberhasilan fibrinolitik yang seperti dijelaskan pada panduan tentang reperfusi pada pasien IMAEST onset dibawah 12 jam, yakni berkurangnya nyeri dada, penurunan elevasi segmen ST lebih dari 50\% dan dijumpainya irama accelerated idioventricular, sayangnya dari ketiga kriteria tersebut hanya irama accelerated idioventricular yang dapat dinilai secara objektif, sementara penurunan elevasi ST tidak dijelaskan apakah jika sudah terbentuk gelombang Q patologis, penurunan tersebut masih tetap bermakna.

Elektrokardiogram 12 sadapan (EKG) sampai saat ini masih dianggap bagian penting dalam penegakkan diagnosis dan evaluasi dini pada pasien dengan IMAEST. EKG merupakan standar baku emas dalam mengidentifikasi lokasi IMAEST bahkan lebih banyak informasi bisa didapatkan dari EKG meliputi ukuran infark dan prognosis penderita IMAEST.5,6 Pada IMAEST dapat dijumpai gambaran khas elevasi segmen ST pada area infark dan disertai dengan gambaran depresi segmen ST (DSST) pada area sadapan di arah yang berlawanan dari area infark (area noninfark) dengan prevalensi sekitar 54\% hingga 82\%.7,8,9 DSST lebih sering terjadi pada IMAEST inferior (72\%) dibandingkan dengan IMAEST anterior (37\%). DSST juga lebih sering pada IMAEST dengan komplikasi dan dengan adanya elevasi segment ST yang cukup besar. ${ }^{10}$

Pada awalnya DSST di sadapan resiprokal area infark pada IMAEST dianggap sebagai benign electrical phenomenon. ${ }^{11,12}$ Dengan berkembangnya teknik angiografi koroner dan pencitraan jantung noninvasif, maka memungkinkan untuk meneliti fungsi ventrikel kanan dan kiri secara global dan segmental pasien IMAEST. ${ }^{11}$ Menggunakan teknik pencitraan ini, banyak penelitian eksperimental yang berusaha membuktikan kebenaran teori bahwa DSST memang merupakan suatu benign electrical phenomenon, namun memberikan hasil yang tidak konsisten. Kebanyakan penelitian berikutnya memberikan alternatif pendapat bahwa DSST pada sadapan resiprokal saat IMAEST menunjukkan infark yang luas pada area yang diperdarahi oleh lesi kulprit, dapat dibuktikan dengan level enzim jantung yang lebih tinggi, abnormalitas gerakan dinding regional ventrikel kiri yang lebih berat dan Ejection Fraction (EF) lebih rendah berbanding pasien tanpa DSST. Pasien dengan DSST cenderung mengalami komplikasi jangka pendek (inhospital) dan panjang serta mortalitas yang lebih tinggi berbanding pasien tanpa DSST. ${ }^{13,14,15,16,17}$

Beberapa penelitian seperti oleh Stevenson dkk, mencoba mengetahui signifikansi DSST di sadapan resiprokal pada elektrokardiogram pasien IMAEST yang di terapi dengan fibrinolitik yang secara klinis dikaitkan dengan prognosis yang lebih buruk. ${ }^{18}$ Penelitian oleh Buller dkk, mencoba mengetahui peranan resolusi DSST dalam memprediksi prognosis pada subjek IMAEST yang menjalani IKP primer mendapatkan kesimpulan bahwa resolusi DSST sesaat setelah IKP primer merupakan suatu parameter yang mudah, murah dan efisien dalam menilai prognosis untuk subjek tersebut. ${ }^{19}$ Penelitian di RS HAM sendiri khusus untuk subjek IMAEST inferior sebelumnya telah diteliti bahwa memang ada tidaknya DSST pada sadapan reciprocal menjadi suatu kondisi yang dapat dijadikan sebagai parameter dalam menentukan prognosis. ${ }^{20}$ Bahkan, untuk subjek dengan IMAEST inferior, penelitian terdahulu menyebutkan bahwa resolusi DSST tampak lebih penting peranannya dalam menentukan prognosis jangka pendek pasien dibandingkan resolusi elevasi segmen ST sendiri. ${ }^{21}$

Melihat pentingnya peran resolusi DSST sebagai salah satu parameter yang sederhana namun sangat efisien dalam meprediksi prognosis pada pasien IMAEST yang menjalani reperfusi dini, maka disini peneliti mencoba untuk mencari perbandingan KKvM untuk subjek IMAEST di RSHAM yang mendapat terapi fibrinolitik dengan atau tanpa adanya resolusi DSST. 
Gambar 1. Kerangka Teori Penelitian

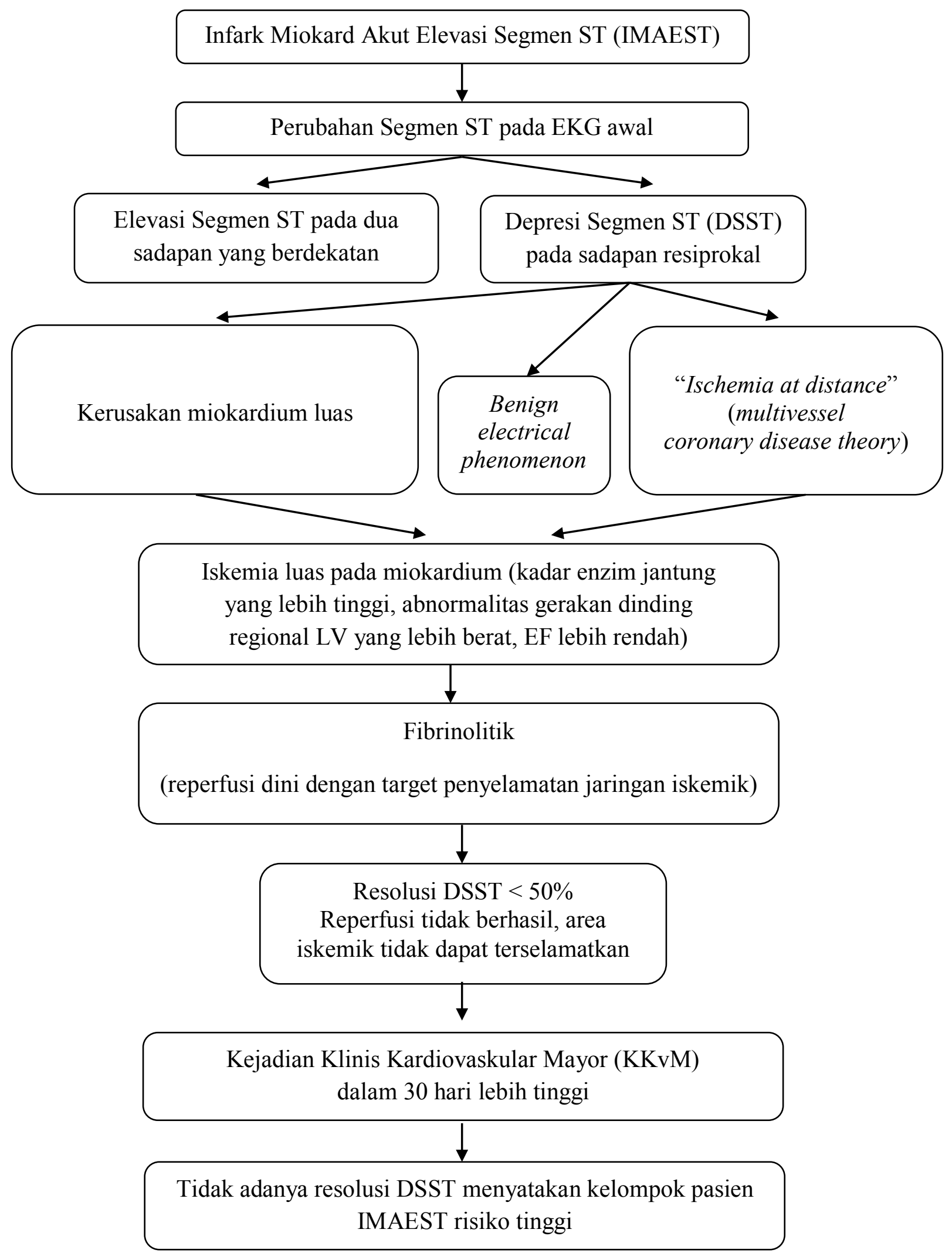




\section{Metode}

\section{Desain Penelitian}

Penelitian ini merupakan studi kohort prospektif dengan populasi penelitian adalah penderita IMAEST yang mendapatkan terapi fibrinolitik alteplase di Departemen Kardiologi RSHAM. Kriteria inklusi adalah pasien dengan diagnosis IMAEST dengan onset kurang dari 12 jam di unit gawat darurat RSHAM dengan adanya gambaran DSST resiprokal pada EKG awal serta mendapatkan terapi fibrinolitik alteplase mulai Maret 2017 sampai Desember 2017, tidak pernah mengalami Infark Miokard Akut (IMA) sebelumnya. Rekaman EKG yang tidak dapat dibaca dengan sempurna dieksklusikan dari penelitian ini. Pemeriksaan EKG 12 sadapan dilakukan pada saat awal masuk unit gawat darurat RSHAM dan 90 menit dari awal mulai terapi fibrinolitik dengan kecepatan rekaman $25 \mathrm{~mm} / \mathrm{s}$ dan skala $10 \mathrm{~mm} / \mathrm{mv}$ menggunakan alat EKG GE MAC 2000.

Jumlah penderita IMAEST mulai Maret 2017 sampai Desember 2017 adalah sebanyak 108 orang, terdapat 48 orang yang tidak diikutsertakan dalam penelitian oleh karena adanya riwayat IMA serta EKG tidak dapat di baca dengan sempurna. Sampel penelitian yang diperoleh adalah sebanyak 60 penderita IMAEST yang telah memenuhi kriteria inklusi dan eksklusi sehingga dapat diikutsertakan dalam penelitian.

\section{Prosedur Penelitian}

Pengumpulan sampel menggunakan metode kuota (consecutive) dimana setiap subyek yang memenuhi kriteria inklusi dan eksklusi dijadikan sampel penelitian. Data dasar, identitas subjek, riwayat penyakit terdahulu dan riwayat penggunaan obat dicatat secara lengkap. Data penting awal yang dievaluasi adalah EKG 12 sadapan pada saat awal masuk unit gawat darurat RSHAM dan 90 menit dari awal mulai terapi fibrinolitik dengan kecepatan rekaman $25 \mathrm{~mm} / \mathrm{s}$ dan skala $10 \mathrm{~mm} /$ mv. DSST pre fibrinolitik dinilai dengan menghitung jumlah dalamnya depresi segmen ST pada sadapan resiprokal yang diukur pada $80 \mathrm{~ms}$ setelah $\mathrm{j}$ point terhadap garis isoelektris. Pengukuran DSST pada EKG akan dilakukan secara manual dengan menggunakan micrometer dial caliper 150 mm Krisbow (KW0600352) dan kaca pembesar. Hasil pengukuran dilaporkan dalam satuan mm. Resolusi DSST resiprokal dilakukan dengan menggunakan rumus :

Resolusi $\sum$ DSST $(\%)=\frac{\sum \text { DSST pre fibrinolitik }-\sum \text { DSST post fibrinolitik }}{\sum \text { DSST pre fibrinolitik }} \times 100$

Berdasarkan pemeriksaan EKG tersebut maka subyek akan dibagi menjadi dua kelompok yaitu kelompok pertama adalah subyek IMAEST tanpa resolusi DSST resiprokal dan kelompok kedua adalah pasien IMAEST dengan resolusi DSST resiprokal. Pengukuran dilakukan oleh residen kardiologi yang bertugas di IGD, kemudian di validasi oleh seorang spesialis jantung dan pembuluh darah tanpa mengetahui identitas pasien.

Kemudian pasien diikuti selama 30 hari kedepan, dilakukan wawancara via telepon dan pemeriksaan lain jika dibutuhkan dan dicatat kejadian dan waktu terjadinya $\mathrm{KKvM}$ berupa gagal jantung, perawatan kembali dan kematian.

\section{Analisis Statistik}

Pengolahan dan analisis data statistik menggunakan perangkat statistik komputer. Variabel kategorik dipresentasikan dengan jumlah atau frekuensi (n) dan presentase (\%). Variabel numerik dipresentasikan dengan nilai rata-rata (mean) dengan standar deviasi untuk data yang berdistribusi normal. Uji normalitas variabel numerik pada seluruh subjek penelitian menggunakan tes Kolmogorov-Smirnov dengan $\mathrm{n}>50$. Perbandingan antara kedua kelompok pada variabel bebas kategorik dan variabel tergantung kategorik menggunakan uji Chi Square. Jika syarat uji Chi Square tidak terpenuhi, maka digunakan uji Fisher. Perbandingan antara kedua kelompok pada variabel bebas kategorik dan variabel tergantung numerik dilakukan dengan uji $\mathrm{T}$ tidak berpasangan. Jika syarat uji $\mathrm{T}$ tidak berpasangan tidak terpenuhi, maka digunakan uji Mann Whitney.

Untuk sampel yang di temukan singnifikan pada uji anaisis bivariat, dimasukkan ke uji multivariat, nilai $\mathrm{p}<$ 0,05 dikatakan bermakna secara statistik. Variabel yang ditemukan mempunyai nilai kemaknaan $\mathrm{p}<0,05$ pada analisis multivariat ditampilkan dalam bentuk Rasio Odds (RO) dengan interval kepercayaan 95\%. Variabel dianggap bermakna jika nilai $\mathrm{p}<0,05$. 


\section{Hasil Penelitian}

\section{Karakteristik Subjek Penelitian}

Subyek penelitian dibagi dalam dua kelompok yaitu kelompok IMAEST dengan resolusi DSST resiprokal (30 orang, $50 \%$ ) dan kelompok IMAEST tanpa resolusi DSST resiprokal (30 orang, 50\%). Usia ratarata subyek penelitian pada kelompok IMAEST dengan resolusi DSST resiprokal adalah 54 tahun berbanding 53 tahun pada kelompok IMAEST tanpa resolusi DSST resiprokal. Sekitar 22 orang $(73,3 \%)$ berjenis kelamin laki-laki pada kelompok IMAEST dengan resolusi DSST resiprokal berbanding 24 orang (80\%) pada kelompok IMAEST tanpa resolusi DSST resiprokal. Rata-rata tekanan darah sistolik (TDS) saat masuk rumah sakit adalah $130 \mathrm{mmHg}$ pada kelompok IMAEST dengan resolusi DSST resiprokal dan 120 mmHg pada kelompok IMAEST tanpa resolusi DSST resiprokal dengan rata-rata frekuensi denyut jantung saat masuk rumah sakit adalah $77 \mathrm{kali} /$ menit pada kelompok IMAEST dengan resolusi DSST resiprokal dan $76 \mathrm{kali} /$ menit pada kelompok IMAEST tanpa resolusi DSST resiprokal.

Dari pemeriksaan laboraturium juga tidak didapati adanya perbedaan yang bermakna secara statistik antara kelompok kelompok IMAEST dengan resolusi DSST resiprokal dan kelompok IMAEST tanpa resolusi DSST resiprokal yaitu jumlah leukosit, ureum dan kreatinin. Tidak dijumpai perbedaan yang bermakna secara statistik dalam faktor-faktor risiko penyakit jantung koroner antara kelompok kelompok IMAEST dengan resolusi DSST resiprokal dengan kelompok IMAEST tanpa resolusi DSST resiprokal.

Hasil Penelitian ini menunjukkan terdapat perbedaan yang bermakna secara statistik antara kelompok IMAEST dengan resolusi DSST resiprokal dan kelompok IMAEST tanpa resolusi DSST resiprokal dalam hal IMAEST anterior dan fraksi ejeksi ventrikel kiri. Kelompok IMAEST dengan resolusi DSST resiprokal jarang terjadi pada IMAEST anterior dibandingkan kelompok IMAEST tanpa resolusi DSST resiprokal yaitu 10 orang $(33,3 \%)$ berbanding 25 orang $(83,3 \%)(\mathrm{p}=<0,001)$. Dalam hal fraksi ejeksi ventrikel kiri terlihat bahwa kelompok IMAEST dengan resolusi DSST resiprokal memiliki nilai fraksi ejeksi ventrikel kiri yang lebih tinggi dari kelompok IMAEST tanpa resolusi DSST resiprokal yaitu 52\% berbanding 43\% $(\mathrm{p}=<0,001)$. Karakteristik dasar subjek penelitian yang diklasifikasi berdasrkan resolusi DSST resiprokal dapat dilihat pada tabel 1 .

Tabel 1. Data Karakteristik Subjek Penelitian. Diklasifikasi Berdasrkan Resolusi DSST Resiprokal

\begin{tabular}{|c|c|c|c|c|}
\hline & \multirow{2}{*}{$\begin{array}{c}\text { Seluruh } \\
\text { Subjek } \\
n=60\end{array}$} & \multicolumn{2}{|c|}{ Resolusi Depresi Segmen ST } & \multirow[b]{2}{*}{ p-value } \\
\hline & & $\begin{array}{c}\text { Ada } \\
\mathrm{n}=30\end{array}$ & $\begin{array}{c}\text { Tidak ada } \\
\mathrm{n}=30\end{array}$ & \\
\hline Umur (tahun) & $54 \pm 9$ & $54 \pm 8$ & $53 \pm 9$ & 0,526 \\
\hline Laki-laki (orang, \%) & $46(77)$ & $22(73,3)$ & $24(80)$ & 0.542 \\
\hline Berat badan $(\mathrm{kg})$ & $70(50-87)$ & $70(50-87)$ & $69(50-85)$ & 0,480 \\
\hline TDS (mmHg) & $129(70-200)$ & $130(100-200)$ & $120(70-170)$ & 0,594 \\
\hline Denyut jantung (kali/menit) & $77 \pm 15$ & $77 \pm 12$ & $76 \pm 17$ & 0,815 \\
\hline Merokok (orang, \%) & $39(65)$ & $18(60)$ & $21(70)$ & 0,417 \\
\hline Diabetes Melitus (orang, \%) & $24(40)$ & $11(36,7)$ & $13(43,3)$ & 0,598 \\
\hline Hipertensi (orang, \%) & $35(58)$ & $16(53,3)$ & $19(63,3)$ & 0,432 \\
\hline Dislipidemia (orang, \%) & $45(75)$ & $25(83,3)$ & $20(66,7)$ & 0,136 \\
\hline Obesitas (orang, \%) & $11(18)$ & $6(20)$ & $5(16,7)$ & 0,739 \\
\hline Anterior IMAEST (orang, \%) & $35(58)$ & $10(33,3)$ & $25(83,3)$ & $<0,001$ \\
\hline Fraksi Ejeksi (\%, \%) & $48(25-60)$ & $52(25-60)$ & $43(26-54)$ & $<0,001$ \\
\hline Leukosit (mm3) & $12647 \pm 3778$ & $13231 \pm 2979$ & $12063 \pm 4411$ & 0,234 \\
\hline Ureum (mg/dl) & $24(9-105)$ & $21(9-105)$ & $25(13-90)$ & 0,426 \\
\hline Kreatinin (mg/dl) & $0,90(0,59-6,61)$ & $0,90(0,59-6,61)$ & $0,89(0,60-3,61)$ & 0,827 \\
\hline
\end{tabular}




\section{Karakteristik Jenis KKvM Subjek Penelitian Diklasifikasi Berdasarkan KKvM}

Jumlah total subjek penelitian adalah 60 orang yang terdiri dari 41 orang yang tidak dijumpai KKvM dan 19 orang dijumpai KKvM dengan proporsi terbanyak subjek yang mengalami gagal jantung 11 orang (18\%) diikuti rehospitalisasi 6 orang $(10 \%)$ dan kematian selama perawatan 4 orang (7\%) dalam 30 hari setelah IMAEST.

\section{Karateristik Hasil Gambaran Elektrokardiografi Subyek Penelitian Diklasifikasi Berdasarkan KKvM}

Hasil elektrokardiografi subyek penelitian menunjukan bahwa terdapat perbedaan yang bermakna secara statistik terhadap kelompok dengan KKvM dan tanpa KKvM pada gambaran elektrokardiografi fragmentasi QRS, resolusi STE, resolusi DSST. Gambaran eletrokardiografi fragmentasi QRS dijumpai pada 13 orang $(68,4 \%)$ kelompok dengan KKvM dan 10 orang $(24,4 \%)$ pada kelompok tanpa KKvM, dengan nilai $\mathrm{p}=0,001$. Gambaran elektrokardiografi resolusi STE di jumpai pada 6 orang $(31,6 \%)$ kelompok dengan KKvM dan 34 orang (82,9\%) pada kelompok tanpa KKvM, dengan nilai $\mathrm{p}<0,001$. Gambaran elektrokardiografi resolusi DSST di jumpai pada 1 orang (5,3\%) kelompok dengan KKvM dan 32 (78\%) pada kelompok tanpa KKvM, dengan nilai $\mathrm{p}<0,001$. Karakteristik hasil gambaran elektrokardiografi subyek penelitian diklasifikasi berdasarkan $\mathrm{KKvM}$ dapat dilihat pada tabel 2.

Tabel2. Data KarakteristikHasil Gambaran Elektrokardiogram Subjek Penelitian. Diklasifikasikan berdasarkan KKvM

\begin{tabular}{lccc}
\hline \multicolumn{1}{c}{ Gambaran EKG } & KKvM (+) & KKvM (-) & p-value \\
\hline Hipertrofi Ventrikel kiri (n, \%) & $1(5,3)$ & $2(4,9)$ & 1 \\
Fragmentasi QRS (n, \%) & $13(68,4)$ & $10(24,4)$ & 0,001 \\
Konfigurasi Rs (n, \%) & $6(31,6)$ & $6(14,6)$ & 0,127 \\
Inversi Gelombang T (n, \%) & $12(62,3)$ & $20(48,8)$ & 0,299 \\
Resolusi STE (n, \%) & $6(31,6)$ & $34(82,9)$ & $<0,001$ \\
Resolusi DSST (n, \%) & $1(5,3)$ & $32(78)$ & $<0,001$ \\
Resolusi T inverse (n, \%) & $3(15,8)$ & $10(24,4)$ & 0,452 \\
Q Path Post (n, \%) & $17(89,5)$ & $33(80,5)$ & 0,385 \\
Resolusi STE dengan Q path & $6(96,7)$ & $28(82,4)$ & 0,264 \\
\hline
\end{tabular}

Perbandingan KKvM dalam 30 Hari Setelah IMAEST yang Mendapatkan Terapi Fibrinolitik Alteplase pada IMAEST dengan Resolusi DSST Resiprokal dan Tanpa Resolusi DSST Resiprokal

Subyek penelitian pada kelompok kelompok IMAEST tanpa resolusi DSST resiprokal memiliki angka kejadian KKvM yang lebih tinggi daripada kelompok IMAEST dengan resolusi DSST resiprokal yaitu 17 orang $(89,5 \%)$ berbanding 2 orang $(10,5 \%)$ dan hal ini bermakna secara statistik dengan nilai $\mathrm{p}<0,001$. Sebaliknya, pada kelompok dengan resolusi DSST resiprokal sekitar 18 orang $(68,3 \%)$ tidak mengalami KKvM berbanding 13 orang $(31,7 \%)$ pada kelompok IMAEST tanpa resolusi DSST resiprokal. Hal ini dapat dilihat pada tabel 3. Lebih lanjut dapat disimpulkan bahwa penderita IMAEST tanpa resolusi DSST resiprokal memiliki kemungkinan 18,3 kali untuk mengalami KKvM dalam 30 hari setelah IMAEST di bandingkan penderita IMAEST dengan resolusi DSST resiprokal. Grafik perbandingan KKvM dalam 30 Hari setelah IMAEST yang mendapatkan terapi fibrinolitik alteplase pada IMAEST dengan resolusi DSST resiprokal dan tanpa resolusi DSST resiprokal dapat di lihat pada gambar 2.

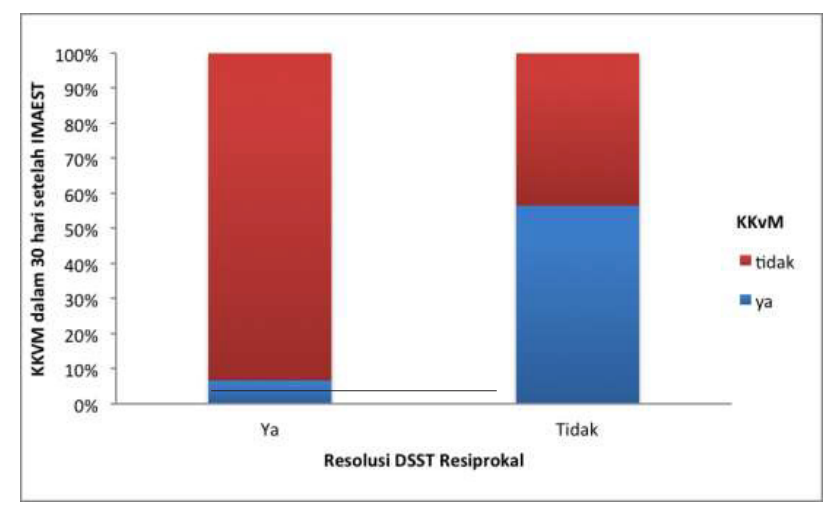

Gambar 2. Grafik perbandingan KKvM dalam 30 Hari setelah IMAEST yang Mendapatkan Terapi Fibrinolitik Alteplase pada IMAEST dengan Resolusi DSST Resiprokal dan Tanpa Resolusi DSST Resiprokal 
Tabel 3. Analisis bivariat resolusi DSST resiprokal terhadap KKvM dalam 30 Hari Setelah IMAEST yang Mendapatkan Terapi Fibrinolitik Alteplase

\begin{tabular}{|c|c|c|c|c|c|}
\hline \multirow{2}{*}{$\begin{array}{c}\text { Resolusi } \\
\text { DSST } \\
\text { Resiprokal } \\
(\mathrm{n}, \%)\end{array}$} & \multicolumn{2}{|c|}{ KKvM } & \multirow[b]{2}{*}{$\mathrm{p}$} & \multirow[b]{2}{*}{ OR } & \multirow[b]{2}{*}{ CI 95\% } \\
\hline & Ya & Tidak & & & \\
\hline $\mathrm{Ya}$ & $2(10,5)$ & $28(68,3)$ & $<0,001$ & 18,31 & $\begin{array}{l}3,67- \\
91,23\end{array}$ \\
\hline Tidak & $17(89,5)$ & $13(31,7)$ & & & \\
\hline
\end{tabular}

\section{Resolusi DSST Resiprokal Sebagai Predik- tor KKvM dalam 30 hari setelah IMAEST yang Mendapatkan Terapi Fibrinolitik Alteplase}

Berdasarkan hasil analisis bivariat resolusi DSST resiprokal terhadap KKvM dalam 30 hari setelah IMAEST yang mendapatkan terapi fibrinolitik alteplase (Tabel 4), dapat disimpulkan bahwa terdapat perbedaan KKvM dalam 30 hari setelah IMAEST yang mendapatkan terapi fibrinolitik alteplase antara penderita IMAEST dengan resolusi DSST resiprokal dan tanpa resolusi DSST resiprokal. Penderita IMAEST tanpa resolusi DSST resiprokal yang mendapatkan terapi fibrinolitik alteplase memiliki angka kejadian KKvM yang lebih tinggi daripada Penderita IMAEST dengan resolusi DSST resiprokal yang mendapatkan terapi fibrinolitik alteplase dan hal ini bermakna secara statistik.

Peneliti ingin mengetahui apakah resolusi DSST resiprokal dapat digunakan sebagai prediktor untuk memprediksi KKvM dalam 30 hari setelah IMAEST pada penderita IMAEST yang mendapatkan terapi fibrinolitik alteplase. Untuk itu peneliti terlebih dahulu harus melakukan analisis bivariat terhadap faktorfaktor lain yang dapat mempengaruhi KKvM dalam 30 hari setelah IMAEST pada penderita IMAEST yang mendapatkan terapi fibrinolitik alteplase. Dari hasil analisis bivariat ini maka terdapat delapan faktor yang memiliki nilai $p<0,05$ yaitu Fraksi ejeksi ventrikel kiri $(\mathrm{p}=0,001)$, faktor risiko merokok, $(\mathrm{p}=0,034)$, Anterior $\operatorname{IMAEST}(\mathrm{p}=0,027)$, Kreatinin $(\mathrm{p}=0,022)$, obat rawat Jalan lengkap $(p=0,004)$, fragmentasi QRS $(p=0,001)$, Resolusi DSST $(\mathrm{p}<0,001)$ dan Resolusi STE $(\mathrm{p}<0,001)$ yang akan dilanjutkan ke analisi multivariat dengan menggunakan uji regresi logistik.

Analisis multivariat dalam penelitian ini berguna untuk mengetahui variabel bebas mana yang paling dominan dan berpengaruh terhadap terjadinya KKvM. Jadi analisis multivariat dilakukan untuk mengetahui faktor-faktor yang dapat dijadikan sebagai prediktor terjadinya KKvM dalam 30 hari setelah IMAEST yang mendapatkan terapi fibrinolitik alteplase. Analisis multivariat menunjukkan bahwa hanya terdapat tiga faktor independen yang dapat memprediksi terjadinya KKvM dalam 30 hari setelah IMAEST yang Mendapatkan Terapi Fibrinolitik Alteplase yaitu Resolusi DSST resiprokal, obat rawat jalan yang lengkap dan kreatinin (Tabel 5). Resolusi DSST resiprokal merupakan faktor yang paling dominan mempengaruhi terjadinya KKvM dalam 30 hari setelah IMAEST yang mendapatkan terapi fibrinolitik alteplase [OR 11.47 (1.14-115.10), $\mathrm{p}=0.038]$.

Tabel 4. Hasil Analisis Bivariat Terhadap KKvM dalam 30 hari setelah IMAEST yang Mendapatkan Terapi Fibrinolitik Alteplase

\begin{tabular}{lcccc}
\hline \multicolumn{1}{c}{ Variabel } & $\begin{array}{c}\text { KKvM }(+) \\
\mathrm{n}(\%)\end{array}$ & $\begin{array}{c}\text { KKvM }(-) \\
\mathrm{n}(\%)\end{array}$ & $\mathrm{p}$ & OR $(95 \% \mathrm{IK})$ \\
\hline TDS $<100 \mathrm{mmHg}$ & $2(10,5)$ & $1(2,4)$ & 0,233 & $4,71(0,40-55,45)$ \\
Fraksi Ejeksi $<$ 40\% & $9(47,4)$ & $4(9,8)$ & 0,001 & $8,32(2,11-32,74)$ \\
Merokok & $16(84,2)$ & $23(56,1)$ & 0,034 & $4,17(1,05-16,57)$ \\
Anterior IMAEST & $15(78,9)$ & $20(48,8)$ & 0,027 & $3,94(1,11-13,90)$ \\
Kreatinin > 1,97 mg/dl & $12(63,2)$ & $13(31,7)$ & 0,022 & $3,69(1,18-11,55)$ \\
Obat rawat jalan lengkap & $6(31,6)$ & $29(70,7)$ & 0,004 & $5,23(1,61-17,01)$ \\
Fragmentasi QRS & $13(68,4)$ & $10(24,4)$ & 0,001 & $6,71(2,02-22,33)$ \\
Resolusi DSST & $2(10,5)$ & $31(75,6)$ & $<0,001$ & $26,35(5,16-134,40)$ \\
Resolusi STE & $6(31,6)$ & $34(82,9)$ & $<0,001$ & $10,5(2,97-37,24)$ \\
\hline
\end{tabular}




\section{Diskusi}

Hasil Gambaran elektrokardiografi yang mempengaruhi KKvM yang bermakna secara statistik adalah Fragmentasi QRS, Resolusi STE dan Resolusi DSST. Data dari percobaan TIMI-4 menunjukkan bahwa fragmentasi QRS memilik ukuran infark lebih besar dan defek yang lebih besar pada scan sestamibi Tc99m dibandingkan pasien yang tanpa adanya bentuk morfologi QRS ini.5 Dalam era IKP primer dan terapi fibrinolitik, resolusi segment ST elevasi pasien dengan IMAEST adalah penanda reperfusi dan patensi arteri koroner (estimasi dari tingkat aliran TIMI) serta terkait dengan ukuran infark yang menjadi lebih kecil. 22,23,24 Namun akhir-akhir ini adanya DSST (di sadapan selain yang pada awalnya menunjukkan elevasi segmen ST) umumnya terlihat pada pasien dengan IMAEST, ada atau tidaknya resolusi DSST setelah IMA juga penting secara prognostik. Ini mencerminkan iskemia di daerah miokard yang lain atau resiprokal dari daerah dengan elevasi segmen ST. Adanya DSST ini dikaitkan dengan infark yang lebih besar dan prognosis yang lebih buruk.5,25,26,27

Tabel 5. Analisis Multivariat KKvM dalam 30 hari setelah IMAEST yang Mendapatkan Terapi Fibrinolitik Alteplase

\begin{tabular}{lccc}
\hline \multicolumn{1}{c}{ Variabel } & OR & IK $(95 \%)$ & $\mathrm{p}$ \\
\hline Resolusi DSST & 11,47 & $1,14-115,10$ & 0,038 \\
Obat rawat jalan & 10,63 & $1,33-84,67$ & 0,026 \\
lengkap & & & \\
Kreatinin & 9,92 & $1,30-75,73$ & 0,027 \\
Resolusis STE & 5,79 & $0,80-41,98$ & 0,083 \\
Fraksi ejeksi & 6,05 & $0,75-48,56$ & 0,090 \\
Merokok & 11,25 & $0,90-140,01$ & 0,060 \\
\hline
\end{tabular}

Hasil perbandingan KKvM dalam 30 hari setelah IMAEST dengan dan tanpa resolusi DSST yang mendapatkan terapi fibrinolitik alteplase menunjukkan bahwa terdapat perbedaan KKvM. Penderita IMAEST tanpa resolusi DSST resiprokal setelah mendapatkan terapi fibrinolitik alteplase memiliki angka kejadian KKvM lebih tinggi dari pada penderita IMAEST dengan resolusi DSST resiprokal setelah mendapatkan terapi fibrinolitik alteplase yaitu 17 orang $(89,5 \%)$ berbanding dengan 2 orang $(10,5 \%)$ dan hal ini bermakna secara statistik dengan nilai $\mathrm{p}<0,001$. Hasil penelitian ini mendukung penelitian sebelumnya dimana kematian di rumah sakit secara signifikan lebih tinggi pada pasien yang mengalami DSST yang menetap setelah resolusi elevasi segmen ST dibandingkan dengan resolusi simultan DSST dan elevasi segmen ST atau yang tidak mengalami DSST (shah dkk,1997). Akhirakhir ini perhatian mulai diarahkan kepada adanya DSST resiprokal pada IMAEST dan resolusi dari DSST resiprokal pada IMAEST. Penelitian telah menunjukkan bahwa pasien dengan IMAEST inferior yang dikaitkan dengan DSST resiprokal memiliki infark yang lebih luas daripada pasien tanpa DSST resiprokal (Becker, 1988). Akhirnya diketahui bahwa tidak hanya elevasi segmen ST dan resolusi elevasi segmen ST saja tetapi DSST resiprokal dan resolusi DSST resiprokal juga berguna untuk memprediksi ukuran infark yang lebih luas serta sebagai pedoman tatalaksana terapi reperfusi baik fibrinolitik ataupun IKP primer.

Lebih lanjut, setelah dilakukan penyesuaian terhadap faktor-faktor lain yang mempengaruhi KKvM dalam 30 hari setelah IMAEST yang mendapatkan terapi fibrinolitik alteplase, maka terlihat bahwa resolusi DSST resiprokal tetap merupakan faktor yang dominan mempengaruhi KKvM dalam 30 hari setelah IMAEST yang mendapatkan terapi fibrinolitik alteplase dibandingkan dengan resolusi STE dengan OR $11,47(1,14-115,10), p=0.038$. Hal ini sejalan dengan penelitian oleh (Tjandrawidjaja dkk, 2010; Wong dkk, 2015; Reinstadler dkk, 2015). Tidak adanya resolusi DSST pada IMAEST yang mendapatkan terapi reperfusi baik fibrinolitik atau IKP primer berhubungan dengan $\mathrm{KKvM}$ yang lebih tinggi. Jadi dapat disimpulkan bahwa resolusi DSST resiprokal dapat digunakan sebagai prediktor untuk memprediksi KKvM dalam 30 hari setelah IMAEST pada penderita IMAEST yang mendapatkan terapi fibrinolitik alteplase.

\section{Kesimpulan}

Penelitian ini menyimpulkan bahwa terdapat perbedaan KKvM dalam 30 hari setelah IMAEST pada penderita IMAEST dengan resolusi DSST resiprokal dan tanpa resolusi DSST resiprokal yang mendapatkan terapi fibrinolitik alteplase, dimana penderita IMAEST tanpa resolusi DSST resiprokal memiliki angka KKvM yang lebih tinggi dibandingkan dengan penderita IMAEST dengan resolusi DSST resiprokal. Resolusi DSST 
resiprokal pada IMAEST yang mendapatkan terapi fibrinolitik alteplase merupakan prediktor yang kuat terhadap KKvM dalam 30 hari dengan OR 11,47.

\section{Keterbatasan Penelitian}

Sampel pada penelitian ini adalah pasien IMAEST dengan adanya DSST yang dilakukan terapi fibrinolitik menggunakan alteplase, dimana secara umum angka prevalensinya lebih rendah dengan berkembangnya fasilitas Rumah sakit dalam melakukan IKP primer sehingga dijumpai kesulitan dalam pengumpulan jumlah sampel minimal. Jumlah sampel dalam penelitian ini lebih kecil dibandingkan dengan penelitian-penelitian yang dilakukan sebelumnya dan hanya dilakukan pada satu tempat penelitian sehingga perlu dilakukan penelitian lebih lanjut dengan jumlah sampel yang lebih besar maupun kerjasama dengan beberapa rumah sakit rujukan yang memiliki fasilitas rawat inap intensif kardiovaskular agar dapat memberikan hasil yang lebih representatif.

\section{Daftar Singkatan}

DSST: Depresi segmen ST

EF: Ejection Fraction

EKG: Elektrokardiogram

IKP : Intervensi Koroner Perkutan

IMA: Infark Miokard Akut

IMAEST: Infark Miokard Akut Elevasi Segmen ST

IMAEST: Infark Miokard Akut Elevasi Segmen ST

KI: Konfidens Interval

KKvM: Kejadian Kardiovaskular Mayor

RO: Rasio Odds

RSHAM: Rumah Sakit Haji Adam Malik Medan

\section{Persetujuan Etik}

Persetujuan Komisi Etik tentang pelaksanaan penelitian kesehatan NO : 321/TGL/KEPK FK USU-RSUP $\mathrm{HAM} / 2017$

\section{Persetujuan untuk Publikasi}

Semua pihak sudah menyetujui publikasi naskah ini.

\section{Konflik kepentingan}

Tidak ada konflik kepentingan dalam penelitian ini.

\section{Pendanaan}

Pendanaan penelitian ini berasal dari Departemen Kardiologi dan Kedokteran Vaskular Fakultas Kedokteran Universitas Sumatera Utara.

\section{Daftar Pustaka}

1. Arso IA. Kejadian Kardiovaskular Mayor Pada Penderita Infark Miokard Akut Dengan Elevasi Segment ST (IMAEST) Yang Dilakukan Terapi Fibrinolitik Dibanding Intervensi Koroner Perkutan (IKP) Primer Selama Perawatan Di Rumah Sakit. Tesis Profesi Ilmu Penyakit Jantung dan Pembuluh Darah FK UGM. 2012.

2. Perhimpunan Dokter Spesialis Kardiovaskular Indonesia. Pedoman Tatalaksana Sindrom Koroner Akut. Edisi Ketiga. Centra Communications. 2014.

3. Steg G, James SK, Atar D, et al. ESC Guidelines for the management of acute myocardial infarction in patients presenting with ST-segmen elevation. European Heart Journal. 2012;2012:1-51.

4. Sarahazti MF. Global Longitudinal Strain (GLS) ventrikel kiri sebagai prediktor kejadian kardiovaskular mayor dalam 30 hari setelah infark miokard akut elevasi segmen ST di Rumah Sakit Haji Adam Malik Medan. Tesis Profesi Ilmu Penyakit Jantung dan Pembuluh Darah FK USU. 2017.

5. Birnbaum Y, Drew BJ. The electrocardiogram in ST elevation acute myocardial infarction: correlation with coronary anatomy and prognosis. Postgard Med J. 2003; 79:490-504.

6. Zimetbaum PJ, Josephson ME. Use of Electrocardiogram in Acute Myocardial Infraction. The New England Journal Of Medicine. 2003;348:933-40.

7. The Lancet. Reciprocal Changes Accompanying Acute Myocardial Infarction. Lancet. 1986:13701371.

8. Noriega FJ, Jorge E, Arzamendi D, et al. Mechanism and diagnostic potential of reciprocal ECG changes induced by acute coronary occlusion in pigs. Journal of Heart Rhythm. 2013:10:883-90. 
9. Ferguson DW, Pandian N, Kioschos JM, et al. Angiographic evidence that reciprocal ST-segment depression during acute myocardial infarction does not indicate remote ischemia : Analysis of 23 patient. The American Journal of Cardiology. 1984;53(1):55-62.

10. Katz R, Conroy RM, Robinson K et al. The aetiology and prognostic implications of reciprocal electrocardiographic changes in acute myocardial infraction. Br Heart J. 1986;55:423-7.

11. Rude RE, Croft CH, Willerson JT. "Reciprocal" anterior ST depression early in the course of transmural inferior myocardial infarction: an ECG finding of uncertain clinical significance. International Journal of Cardiology. 1983;4:80-85.

12. Berger PB, Ryan TJ. Inferior myocardial infraction: high-risk subgroups. Circulation. 1990;81:401411.

13. Jennings K, Reid DS, Julian DG. "Reciprocal” depresision of ST segment in acute myocardial infarction. Br Med J. 1983;287:634-637.

14. Gelman JS, Saltrup A. Pericordial ST depression in pateients with inferior infarction: clinical implications. Br Heart J. 1982;7:133-139.

15. Herlitz J, Hjalmarson H. Occurence of Anterior ST depression in Inferior Myocardial Infarction and relation to clinical outcome. Clin Cardiol. 1987;(10):529-534.

16. Hasdai D, Sclarovsky S, Solodky A, et al. Prognostic significance of maximal pericordial ST segment depression in right (V1-V3) versus left (V4-V6) leads in patients with inferior wall acute myocardial infarction. The American Journal Cardiology. 1994;74(11):1081-1084.

17. Forfar JC. Reciprocal ST segment changes in acute myocardial infarction: informative or incidental?. Quarterly Journal of Medicine. 1989;72:763-765.

18. Stevenson RN, Ranjadayalan K, Umachandran V, et al. Significance of reciprocal ST depression in acute myocardial infarction: a study of 258 patients treated by thrombolysis. Br Heart J. 1993;69:211-214.

19. Buller CE, Fu Y, Adams P, et al. ST-Segment Recovery and Outcome After Primary Percutaneous Coronary Intervention for ST-Elevation Myocardial Infarction: Insight From the Assessment of Pexelizumab in Acute Myocardial Infarction (APEXAMI) Trial. Circulation. 2008;1 18:1335-1346.
20. Suganti J. Perbandingan Kejadian Klinis Kardiovaskular Mayor Selama Perawatan di Rumah Sakit Pada Penderita Infark Miokard Akut Elevasi Segment ST Inferior dengan dan Tanpa Depresi Segment ST Perikordial di Rumah Sakit Haji Adam Malik Medan. Tesis Magister Ilmu Penyakit Jantung dan Pembuluh Darah FK USU. 2016.

21. Wong CK, Gao W, White HD. Resolution of ST depression after fibrinolysis can be more important than resolution of ST elevation for many patients with inferior STEMIs. International Journal of Cardiology. 2015;182:232-234.

22. Antman EM. "ST-Segment Elevation Myocardial: Pathology, Pathophysiology and Clinical Features". In: Braunwald E, Bonow RO, Mann DL, Zipes DP, Libby P, eds. Braunwald's Heart Disease: A textbook of Cardiovascular Medicine. 9th ed. Philadelphia: Elsevier; 2012:1087-1111.

23. De Lemos JA, Braunwald E. ST segment resolution as a tool for assessing the efficacy of reperfusion therapy. J Am Coll Cardiol. 2001;38:1283.

24. Angeja BG, Gunda M, Murphy SA, et al. TIMI myocardial perfusion grade and ST segment resolution: association with infarct size as assessed by single photon emission computed tomography. Circulation. 2002;105:282.

25. Hathaway WR, Peterson ED, Wagner GS, et al. Prognostic Significance of the Initial Electrocardiogram in Patients With Acute Myocardial Infarction. GUSTO-I Investigator. J of Am Med Association. 1998;279(5):387-391.

26. Peterson ED, Hathaway WR, Zabel KM, et al. Prognostic significance of pericordial ST Segment depression during inferior myocardial infarction in the thrombolytic era: results in 16.521 patients. J Am Coll Cardiol. 1996;28:305.

27. Birnbaum Y, Kloner RA, Sclarovsky S, et al. Distortion of the terminal portion of the QRS on the admission electrocardiogram in acute myocardial infarction and correlation with infarct size and long-term prognosis (TIMI-4 Trial). Am J Cardiol. 1999;78:396. 